\title{
PRODUCTION AND PROPERTIES OF SOLID BIOCHAR FROM OIL PALM TRUNK WASTE USING SUB-CRITICAL WATER TECHNOLOGY
}

\author{
NOOR AZURA MUDA*; HIROYUKI YOSHIDA*; HAZWANI ISHAK*; MOHD HALIM SHAH ISMAIL* and \\ SHAMSUL IZHAR*
}

\begin{abstract}
Sub-critical water (sub-CW) technology was utilised to produce solid biochar (SB) from oil palm trunk $(O P T)$. This study evaluated the production of SB from sub-CW treatment of the top and bottom parts of 21and 35-year old OPT. The SB production and its properties were assessed by means of higher heating values, elemental analysis, scanning electron microscopy, and particle size distribution. Treatment of the OPT21T at $300^{\circ} \mathrm{C}$ for 5 min produced a high yield of $S B$ at $0.18 \mathrm{~kg} \mathrm{~kg}$-dry OPT $T^{-1}$. The highest higher heating value (HHV) of SB was $32.4 \mathrm{MJ} \mathrm{kg}^{-1}$ from the treatment of OPT21B at $340^{\circ} \mathrm{C}$ for $5 \mathrm{~min}$. The SB had higher $\mathrm{HHV}$ than petroleum coke but was within the range of general-purpose coal. Elemental analysis of SB revealed the occurrence of carbonisation and the extent of pyrolysis reaction judging from increasing the carbon value of $S B$ with increasing temperature. The particle size distribution of $S B$ at $370^{\circ} \mathrm{C}$ and 5 min reaction time was in the range between 8 and $10 \mu \mathrm{m}$. Consequently, sub-CW is a promising technology to convert waste oil palm trunks into micro-particle SB with high HHV for possible use as alternative fuel and for improving soil productivity.
\end{abstract}

Keywords: sub-critical water (sub-CW) technology, pyrolysis, oil palm trunk, solid biochar (SB), micro-particle biochar.

Date received: 24 January 2019; Sent for revision: 2 March 2019; Accepted: 8 October 2019; Available online: 18 August 2020.

\section{INTRODUCTION}

The implementation of biomass-derived carbon neutral energy as a new energy source and as a soil amendment has gained worldwide attention. These were due to the depletion of fossil sources and alarming environmental concern. The continued consumption of fossil fuels has led to unavoidable aggravation to the environment and human health. Malaysia is the world's second largest producer of palm oil, with oil palm plantations covering nearly $20 \%$ of total land area (Dayang Nazrima, 2017). The

Department of Chemical and Environmental Engineering, Universiti Putra Malaysia, 43400 UPM Serdang,

Selangor, Malaysia.

E-mail: shamizhar@upm.edu.my oil palm must be replanted every 25-30 years to maintain the continuous production of fresh fruit bunches of oil palm (Kalyana and Basiron, 2017). A massive amount of oil palm trunk (OPT) and oil palm fronds $(\mathrm{OPF})$ are available during the largescale replanting process. With the projected area of around 235277 ha of old oil palm undergoing replanting in 2024, Malaysia will have 17.76 million tonnes of dry matter from OPT waste (Ibrahim, 2012). Most of the OPT are currently being buried or left to rot on-site, while some OPF were used as a ruminant food together with small portion of OPT (Kee, 2004). This study will be using OPT as feedstock instead of OPF because of OPF has been commercially used as a ruminants food. The massive amount of OPT will create an unavoidable waste disposal issues. Rather 
than disposing OPT waste into landfills, advanced technology can convert this waste into value-added materials and this will solve or reduce the waste disposal problem. The OPT is made up of a small portion of the hard-outer layer and a large part of the high moisture inner layer. Currently, the outer layer is utilised as lumber in plywood manufacturing (Jalil et al., 2011) and the inner layer can be used for bio-oil (Muda et al., 2019), bio-methanol and bioethanol production (Hossain and Jalil, 2016; Kosugi et al., 2010; Lam et al., 2009; Norhazimah and Faizal, 2014; Yamada et al., 2010).

Biochar refers to the solid product produced by the complete or partial decomposition of biomass component and a mineral fraction. The properties of biochar depend on the pyrolysis technique and the type of feedstock. Slow pyrolysis process at a temperature range between $300^{\circ} \mathrm{C}-800^{\circ} \mathrm{C}$ favours the production of biochar, where the primary products obtained consist of $30 \mathrm{wt} \%$ bio-oil, $35 \mathrm{wt} \%$ biochar, and $35 \mathrm{wt} \%$ gases (Kan et al., 2016). Biochar is inexpensive, environmental-friendly, and possess multipurpose uses like soil remediation, waste management, greenhouse gas reduction, and energy production (Sun et al., 2016). Demirbas et al. (2004) reported the elemental composition of biochar carbon was 53\%-96\%, higher heating value (HHV) ranging in between 20-36 MJ kg-1 and yields of about 30-90 wt \% from pyrolysis of different biomass feedstocks at different temperatures and heating rates. Biochar can be obtained by various methods including pyrolysis, gasification, hydrothermal carbonisation and torrefaction treatment (Sun et al., 2016). All the above method required high reaction temperature $\left(350^{\circ} \mathrm{C}\right.$ and above), longer reaction time $(1 \mathrm{hr})$, and also required pre-treatment $(12 \mathrm{hr}$ of drying process) compared to sub-critical water (subCW) technology.

Liu and Han (2015) reported on the production of solid fuel biochar from pine wood and coconut fibre in a low pyrolysis condition where, the coconutderived solid fuel biochar showed lower energy density and lower energy yield than pine wood. The optimal temperatures for fuel production was $300^{\circ} \mathrm{C}$ for coconut fibre and $330^{\circ} \mathrm{C}$ for pine wood. Another study by Liu et al. (2013) on hydrothermal carbonisation of coconut fibre and dead eucalyptus leaves to produce solid fuel biochar, reported that the energy density of coconut fibre increased with increasing temperature with higher heating values close to lignite.

Biochar in soil acts as a remediation agent to enhance the plant uptake of nutrient and water. The high surface area and porosity of biochar compared to other soil amendment enable it to retain and absorb nutrient, water and also provides a habitat for the beneficial microorganism to flourish (Hunt et al., 2010). Study by Zhang et al. (2012) had demonstrated the usage of wheat straw biochar (total N: $0.59 \%$; surface area $8.92 \mathrm{~m}^{2} \mathrm{~g}^{-1}$; ash content: $20.8 \%$ and $2 \mathrm{~mm}$ size fraction) as a soil amendment had enhanced the rice productivity by $10 \%$ in the first year and $9.5 \%$ $29 \%$ in the subsequent years. The soil $\mathrm{pH}$, soil organic carbon and total nitrogen also increased with biochar treatment. The addition of birch wood biochar [carbon (C): $77.83 \%$; nitrogen (N): 0.77\%; BrunauerEmmett Teller (BET) surface area: $3.6 \mathrm{~m}^{2} \mathrm{~g}^{-1}$ and $<10$ $\mathrm{mm}$ sized fraction] into soil had increased the $\mathrm{CH}_{4}$ intake by $96 \%$ and increased the soil water holding capacity by $11 \%$ without a significant different in $\mathrm{CO}_{2}$ and $\mathrm{NO}_{2}$ emission (Karhu et al., 2011). Dugan et al. (2010) reported the implementation of sawdust and maize stover biochar in the sandy texture soil also had improved the water holding capacity of the soil. The amendment of oak wood biochar (C: $90 \%$; $\mathrm{N}: 0.3 \%$; and ash content: $4.3 \%$ ) in soil had increased the soil $\mathrm{pH}$, increased the soil-C by $7 \%$, increased sub-nanopore surface area by $15 \%$ and reduce soil bulk density by $13 \%$ compared to the control soil. Biochar amendment in the land also showed a decrement in cumulative $\mathrm{NO}_{2}$ emission with no sign in total cumulative $\mathrm{CH}_{4}$ and $\mathrm{CO}_{2}$ emission. The global warming potential had shown an adverse effect (Mukherjee et al., 2014).

The sub-CW is referred to water in liquid state, at temperature between its boiling $\left(100^{\circ} \mathrm{C}\right)$ and critical points $\left(374^{\circ} \mathrm{C}\right)$ and the pressure $(22 \mathrm{Mpa})$ higher than its saturated vapour pressure. The sub$\mathrm{CW}$ water becomes a suitable solvent for extracting non-polar compound and acts as an acid-catalysed medium. The low dielectric constant of sub-CW at above $250^{\circ} \mathrm{C}$ exhibits similar behaviour as methanol and ethanol solvents at room temperature (Luque de Castro et al., 1999; Shitu et al., 2015). Meanwhile, the presence of high ion production at $250^{\circ} \mathrm{C}(\log$ $\mathrm{K}_{\mathrm{w}}=10^{-11} \mathrm{~mol}^{2}$ litre $^{-2}$ ), provides an acidic medium for hydrolysis reaction and also acts as an acid catalyst (Shitu et al., 2015; Yoshida et al., 2018). The sub-CW technology is an environmental-friendly technology, requires low operation cost, milder operation temperature and time and produces non-toxic waste since it uses water as a solvent. Drying, grinding, and separation of feedstock are unnecessary because sub-CW technology can use wet and mixed feedstock (Peterson et al., 2008; Valdez et al., 2011).

Solid biochar (SB) from OPT waste seems to have the potential to become solid fuel biochar and also as a soil amendment, however, there is no recent study on this. Thus, we carried out a study to convert OPT using sub-CW by taking the advantages of its high activity for hydrolysis and pyrolysis to produce SB. The effect of reaction temperature on the output of SB production was studied, and the properties of SB were analysed. The HHV of SB was measured to determine the potential of SB as solid fuel biochar, and the surface morphology of SB was done to determine the suitability of SB as soil enrichment. 


\section{MATERIALS AND METHODS}

\section{Materials}

Two different ages of OPT were taken from 21- and 35-year old oil palm. Both oil palm trunks were cut into two parts, top ( $7 \mathrm{~m}$ from ground) and bottom part ( $1 \mathrm{~m}$ from ground). The inner section for both parts was used due to the large volume of the inner section, and it was less utilised compared to the outer section. Moisture contents for both parts were determined by drying the samples in an oven at $55^{\circ} \mathrm{C}$ (set-temperature) until the moisture content remained constant (Kurnin et al., 2016). The inner section was cut into small cubes ( $5 \mathrm{~mm} \times 5 \mathrm{~mm} \times 5$ $\mathrm{mm}$ ) and these cube samples were used immediately for sub-CW reaction. The rest of the samples were stored in the freezer to avoid deteriorations. The top and bottom parts of 21 years old OPT were denoted as OPT21T and OPT21B, respectively, and the top and bottom parts of 35 years old OPT were denoted as OPT35T and OPT35B, respectively.

\section{Methods}

Solid biochar preparation. The sub-CW reactor consisted of a stainless-steel tube (SUS316, i.d. $0.008 \mathrm{~m} \times 0.15 \mathrm{~m}$ ) fitted with Swagelok-caps at both ends. The total volume of the reactor was $8.0 \times 10^{-6}$ $\mathrm{m}^{3}$. Initially, one side of the tube was sealed with a Swagelok cap, and then $2.5 \times 10^{-3} \mathrm{~kg}$ of OPT sample and $3.5 \times 10^{-3} \mathrm{~kg}$ ultra-pure water were filled into the reactor tube. Argon gas was purged into the reactor to remove air in the reactor and then the reactor was sealed by a Swagelok cap. The sealed reactor tube was immediately immersed into a preheated molten salt bath (Thomas Kagaku Co. Ltd, Japan) containing a mixture of potassium nitrate and sodium nitrite with a 1:1 ratio. Reactions were carried out at temperatures between $250^{\circ} \mathrm{C}-370^{\circ} \mathrm{C}$. After $5 \mathrm{~min}$, the reactor was taken out from the molten salt bath and immediately quenched in room temperature water bath to stop further reactions inside the reactor (Pourali, 2010; Pourali et al., 2009).

The reactor contents of aqueous phase and residual solid was poured into pre-weighed empty centrifuge tube. The aqueous phase and residual solid was separated by centrifugation for $5 \mathrm{~min}$ at $4000 \mathrm{rpm}$. The aqueous portion was recovered into a pre-weighed bottle by using a pasture pipette. Ultra-pure water was then added into the centrifuge tube and centrifuged again for $5 \mathrm{~min}$ at $4000 \mathrm{rpm}$. This washing procedure was repeated until the aqueous portion became colourless. After the washing procedure, the reactor with one open end together with other capped end and the centrifuge tube containing residual solid was dried in an oven at $55^{\circ} \mathrm{C}$. The acetone solution was used to recover acetone soluble materials inside the reactor wall and in the residual solid. The acetone solution was added into the reactor and then transferred into the centrifuge tube containing residual solid. The content was mixed using a tube mixer for $2 \mathrm{~min}$ followed by centrifugation for $5 \mathrm{~min}$ at $4000 \mathrm{rpm}$. The acetone phase was recovered using a pasture pipette into a pre-weighed glass bottle. This procedure was repeated until the acetone phase turned colourless (Pourali, 2010; Pourali et al., 2009). Finally, the SB was obtained by evaporating acetone from the residual solid in a fume hood (ambient temperature for 72 $\mathrm{hr}$ ), and the produced SB was weighed. The yield of $\mathrm{SB}$ was determine by using the Equation (1) below:

$$
\text { Yield of SB }=\frac{\text { W2-W1 }}{\begin{array}{c}
\text { Dry weight of OPT } \\
\text { (kg-dry OPT) }
\end{array}}
$$

where:

W1- weight of pre-weighed empty centrifugal tube.

W2- weight of centrifugal tube contained SB.

Proximate and ultimate analysis of OPT waste. The HHV was determined using oxygen bomb calorimeter (Parr instrument Co., model 1341, USA). The compositions of carbon, hydrogen, nitrogen and sulphur was analysed using CHNSanalyser (Leco Co., CHNS628, USA). Composition of hemicellulose and cellulose was determine using a modified of acid hydrolysis, alkali hydrolysis and organosolv process as reported by Ortega (2015). The composition of lignin was determined by the different of hemicellulose and cellulose.

Characterisation of $S B$. The particle size distribution of $\mathrm{SB}$ was measured using particle size distribution analyser (Malvern Instrument Ltd, Hydro 2000MU, UK) and surface morphology images were taken by scanning electron microscope (Hitachi, S-3400N, US). The ash content was measured by igniting the $\mathrm{OPT}$ samples at $800^{\circ} \mathrm{C}$ in a furnace.

\section{RESULTS AND DISCUSSION}

\section{Proximate and Ultimate Analysis of OPT Waste}

The major components of biomass including OPT waste are hemicellulose, cellulose and lignin. These significant components decompose at different rates and distinct temperatures. The decomposition of hemicellulose occurs at $220^{\circ} \mathrm{C}$ and reaches complete decomposition around $315^{\circ} \mathrm{C}$. Then, the decomposition of cellulose takes place from $315^{\circ} \mathrm{C}$ to $400^{\circ} \mathrm{C}$. Lignin decomposition occurs at the same time as cellulose, but complete decomposition is achieved at $900^{\circ} \mathrm{C}$. The decomposition of hemicellulose, cellulose and lignin, are a product in 
gas, aqueous and solid phases, respectively (Yang et al., 2007). Table 1 shows the proximate and ultimate analysis of the OPT samples used. The moisture and ash content were found highest in OPT21B. The presence of high ash content contributes to high solid product and high non-condensable gases (Venderbosch and Prins, 2010). The C, H, N, $\mathrm{S}$ and $\mathrm{O}$ in OPT21T and OPT21B contain almost the same amount: carbon, $40 \mathrm{wt} \%-44 \mathrm{wt} \%$ : hydrogen, 6.20 wt $\%-6.56$ wt $\%$ : nitrogen, 0.12 wt $\%-0.19$ wt $\%$ : sulphur, $0.05 \mathrm{wt} \%$ and oxygen, $49 \mathrm{wt} \%-50 \mathrm{wt} \%$. The oxygen content was found to be higher than $\mathrm{C}, \mathrm{H}$, $\mathrm{N}$, and S. The HHV value for both part of OPT21T and OPT21B also were almost the same, which was 16.6 $\mathrm{MJ} \mathrm{kg}^{-1}-18.1 \mathrm{MJ} \mathrm{kg}^{-1}$.

\section{Yield of SB}

The yield of SB depends on the decomposition behaviour of cellulose and lignin during the sub-CW reaction. Hemicellulose content is not considered as an essential factor to the yield of SB because hemicellulose decompose over a low-temperature range $\left(220^{\circ} \mathrm{C}-315^{\circ} \mathrm{C}\right)$, thereby contributing more towards the yield of noncondensable gases especially at high temperature (Yang et al., 2007). Cellulose is the most significant factor in determining the SB yield due to the faster mass loss rate of cellulose $\left(6.5 \mathrm{wt} \%{ }^{\circ} \mathrm{C}^{-1}\right)$ than other components (Abnisa et al., 2013b). The second most important factor is lignin as it decomposes over a wide range of temperature with low mass loss rate regarding aromatic ring and various branches of lignin structure (Yang et al., 2007). Therefore, OPT part that contains high cellulose content has high SB yield. It can be seen in Figure 1 a where the yield of SB at $370^{\circ} \mathrm{C}$ of OPT21T (cellulose: $33.91 \%$; lignin: $37.22 \%$ ) and OPT21B (cellulose: $31.91 \%$; lignin: $44.77 \%$ ) were about $7.1 \%$ and $5.4 \%$, respectively. The presence of high ash contributes to the low yield of bio-oil and a high yield of SB and non-condensable gases (Venderbosch and Prins, 2010). The effect of ash content was observed in Figure 1, where OPT21T and OPT35T with ash content at about $1.7 \%$ and $1.08 \%$, producing about $7.1 \%$ and $5.5 \%$ yield of $\mathrm{SB}$ at $370^{\circ} \mathrm{C}$, respectively.

Figures $1 a$ and $1 b$ show the effect of the reaction temperature on the yield of SB produced by sub$\mathrm{CW}$ reaction at $5 \mathrm{~min}$ reaction time. As temperature increased, the decomposition of OPT increased due to an increase of hydrolysis and pyrolysis activity in sub-CW and lowered the yield of SB. The decrease in the yield of SB was accompanied by an increase in the formation of valuable materials in the water-soluble phase and acetone phase. In Figure 1a, the decomposition of OPT21T could easily be compared to that of OPT21B. However, the decomposition of OPT35T and OPT35B was almost the same. The yield of SB was determined starting from reaction temperature of $300^{\circ} \mathrm{C}$ and above because, at a reaction temperature below $300^{\circ} \mathrm{C}$, visual observation showed un-decomposed OPT. Non-decomposed OPT maybe because the pyrolysis activity of sub-CW was not dominant at a temperature below $300^{\circ} \mathrm{C}$. These temperatures are consistent with the literature where the favourable condition for the production of biochar is in the temperature range of $300^{\circ} \mathrm{C}$ (Kan et al., 2016; Liu and Han, 2015).

The SB yield obtained from OPT21T and

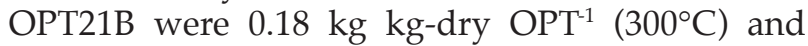
$0.11 \mathrm{~kg} \mathrm{~kg}$-dry $\mathrm{OPT}^{-1}\left(310^{\circ} \mathrm{C}\right)$, respectively. While in OPT35T and OPT35B, the yield of SB was 0.15 kg kg-dry $\mathrm{OPT}^{-1}\left(300^{\circ} \mathrm{C}\right)$ and $0.12 \mathrm{~kg} \mathrm{kg-dry} \mathrm{OPT}^{-1}$ $\left(340^{\circ} \mathrm{C}\right)$, respectively. There was not any significant difference between SB yield of both ages of the OPT tested. Since the OPT was less productive after 21 years, the SB from the OPT21T and OPT21B were chosen for further study.

\section{HHV of SB}

$\mathrm{HHV}$ was measured using oxygen bomb calorimeter to classify the SB obtained. Figure 2 shows the HHV of SB obtained from the OPT21T and OPT21B after treatment with sub-CW. From the graphs, it can be seen that the value of HHV increased with increasing temperature. This increment of $\mathrm{HHV}$ indicates successful carbonisation

TABLE 1. PROXIMATE AND ULTIMATE ANALYSIS OF FRESH OIL PALM TRUNK (OPT)

\begin{tabular}{|c|c|c|c|c|c|c|c|c|c|c|c|}
\hline \multirow[t]{2}{*}{ Property } & $\begin{array}{c}\text { Moisture } \\
\text { content } \\
\text { (oven dried) }\end{array}$ & Ash & $\mathrm{C}$ & $\mathbf{H}$ & $\mathbf{N}$ & $\mathrm{S}$ & $\mathrm{O}^{*}$ & Hemicelluloses & Cellulose & Lignin $^{* *}$ & \multirow{2}{*}{$\begin{array}{c}\text { Higher } \\
\text { heating } \\
\text { value }\end{array}$} \\
\hline & \multicolumn{2}{|c|}{$(\mathbf{w t} \%)$} & \multicolumn{5}{|c|}{$(\mathbf{w t} \%)$} & \multicolumn{3}{|c|}{$(\mathbf{w t} \%)$} & \\
\hline OPT21T & 63.6 & 1.7 & 40.38 & 6.56 & 0.12 & 0.05 & 52.89 & 28.87 & 33.91 & 37.22 & 16.6 \\
\hline OPT21B & 83.6 & 3.2 & 44.52 & 6.20 & 0.19 & 0.05 & 49.04 & 23.32 & 31.91 & 44.77 & 18.1 \\
\hline ОРТ35T & 80.9 & 1.08 & nd & nd & nd & nd & nd & nd & nd & nd & nd \\
\hline ОРТ35В & 76.6 & 0.65 & nd & nd & nd & nd & nd & nd & nd & nd & nd \\
\hline
\end{tabular}

Note: * Oxygen $(\mathrm{O})=100$ carbon $(\mathrm{C})$ - hydrogen $(\mathrm{H})$ - nitrogen $(\mathrm{N})$ - sulphur $(\mathrm{S})$.

** By difference.

nd - not determined. 

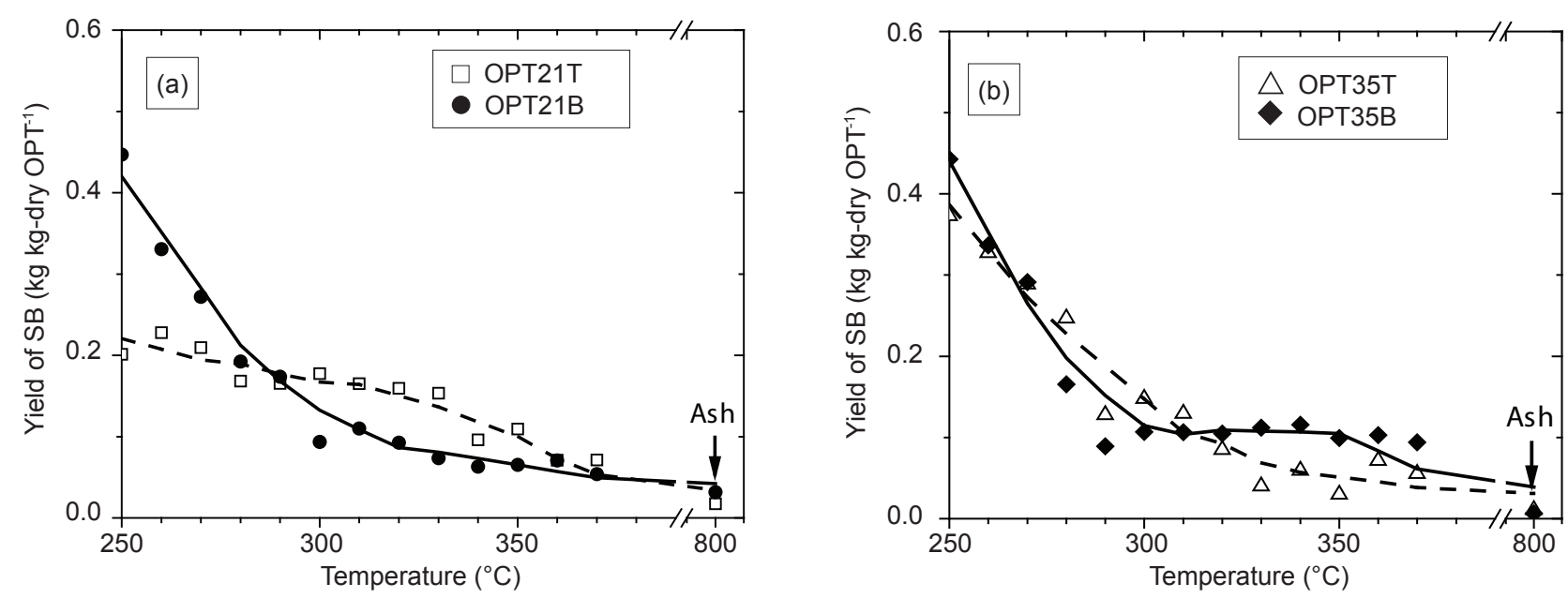

Figure 1. Effect of reaction temperature on the yield of solid biochar (SB) produced by sub-critical water (sub-CW) treatment for 5 min: (a) 21-year old oil palm trunk (OPT) top section (OPT21T), and bottom section (OPT21B); (b) 35-year old OPT top section (OPT35T) and bottom section (OPT35B).

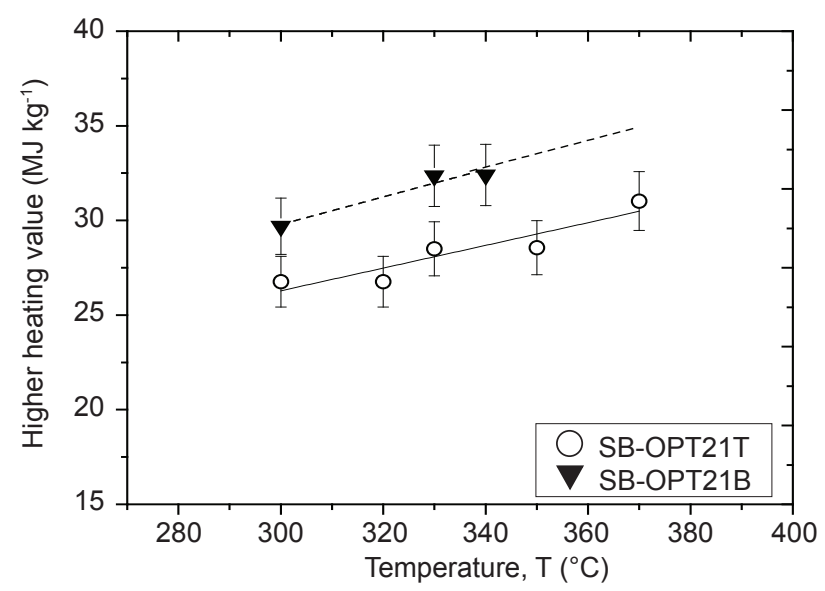

Figure 2. Higher heating value (HHV) of solid biochar (SB) after sub-critical water (sub-CW) treatment of 21-year old oil palm trunk (OPT) top section (OPT21T) and 21-year old OPT bottom section (OPT21B) at various temperatures.

of OPT to SB. The data in each sample could be correlated by a straight line in the following Equations (2) and (3), for OPT21T and OPT21B, respectively.

$$
\begin{array}{ll}
\mathrm{HHV}=60 \mathrm{~T}+8280 & \text { Equation (2) } \\
\mathrm{HHV}=73 \mathrm{~T}+8020 & \text { Equation (3) }
\end{array}
$$

Where $T$ is the reaction temperature in ${ }^{\circ} \mathrm{C}$. The standard error of the slopes is 14.1 (OPT21T) and 16.8 (OPT21B). The $\mathrm{R}^{2}$ values are 0.81 for OPT21T and 0.89 for OPT21B, thus, showing a good correlation between the HHV and the sub-CW treatment temperature. These results showed that the quality of SB in term of HHV was increased with the extent of sub-CW reaction. As sub-CW reaction deepened (higher temperature), the HHV of SB is increases.

Table 2 compares the HHV of OPT-derived SB with other solid fuels. The HHV of untreated dry OPT range from $16 \mathrm{MJ} \mathrm{kg}^{-1}-18 \mathrm{MJ} \mathrm{kg}^{-1}$. The HHV of SB obtained from sub-CW reaction of OPT21T and OPT21B were between the range of $25 \mathrm{MJ}$ $\mathrm{kg}^{-1}-32.5 \mathrm{MJ} \mathrm{kg}^{-1}$. The HHV of untreated OPT21T and OPT21B (dry OPT) with sub-CW reaction was found to be higher than wood (dry) and coal (lignite-anthracite). In OPT21T, the highest HHV of SB $\left(370^{\circ} \mathrm{C}\right)$ was higher than commercial biochar and close to petroleum coke.

Meanwhile, the lowest $\mathrm{HHV}$ of $\mathrm{SB}\left(320^{\circ} \mathrm{C}\right)$ was higher than low-temperature coke (15\% water) and in the range of coal (lignite-anthracite). The average $\mathrm{HHV}$ of SB resulting from sub-CW treatment was closer to commercial biochar. In OPT21B, the highest HHV of SB was higher than petroleum coke and was in the range of general-purpose coal (5\%$10 \%$ water). The lowest HHV of SB was similar to commercial biochar, and the average HHV of SB was similar to petroleum coke. The HHV of SB obtained signifies that sub-CW treatment was able to convert OPT into solid fuel with good HHV equivalent to many natural charcoals derived from biomass. 
TABLE 2. COMPARISON BETWEEN HIGHER HEATING VALUE (HHV) OF SOLID BIOCHAR (SB) PRODUCED BY SUB-CRITICAL WATER (sub-CW) TREATMENT WITH HHV OF COMMON SOLID FUELS

\begin{tabular}{lcc}
\hline \multicolumn{1}{c}{ Type of fuel } & \multicolumn{2}{c}{ Higher heating value $\left.\mathbf{~ ( M J ~ k g ~}^{-1}\right)$} \\
\cline { 2 - 3 } Untreated OPT (dried) & OPT21T & 18.1 \\
Treated OPT highest HHV (sub-CW temperature) & 16.6 & $32.4\left(340^{\circ} \mathrm{C}\right)$ \\
Lowest HHV & $31\left(370^{\circ} \mathrm{C}\right)$ & $29.7\left(300^{\circ} \mathrm{C}\right)$ \\
Average of HHV & $26.8\left(320^{\circ} \mathrm{C}\right)$ & $31.5^{*}$ \\
\hline Other solid fuels & $28.3^{*}$ & HHV $\left(\mathrm{MJ} \mathrm{kg}^{-1}\right)$ \\
\hline Peat & $13.8-20.5^{\mathrm{a}}$ \\
Wood (dry) & $14.4-17.4^{\mathrm{a}}$ \\
Coal (lignite-anthracite) & $15-27^{\mathrm{a}}$ \\
Bituminous coal & $17-23.25^{\mathrm{a}}$ \\
Low temperature coke $(15 \%$ water $)$ & $26^{\mathrm{b}}$ \\
Commercial biochar & $29.6^{\mathrm{a}}$ \\
Petroleum coke & $31.3^{\mathrm{c}}$ \\
General purpose coal $(5 \%-10 \%$ water $)$ & $32-42^{\mathrm{b}}$ \\
\hline
\end{tabular}

Note: *Average of $\mathrm{HHV}$ from temperature $300^{\circ} \mathrm{C}, 320^{\circ} \mathrm{C}, 330^{\circ} \mathrm{C}, 340^{\circ} \mathrm{C}, 350^{\circ} \mathrm{C}, 360^{\circ} \mathrm{C}$ and $370^{\circ} \mathrm{C}$. OPT - oil palm trunk.

Source: ${ }^{a}$ http: / / www.engineeringtoolbox.com/fuels-higher-calorific-values-d_169.html

${ }^{\mathrm{b}}$ US Department of Energy (2011).

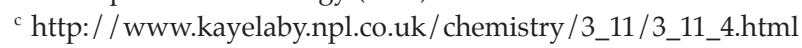

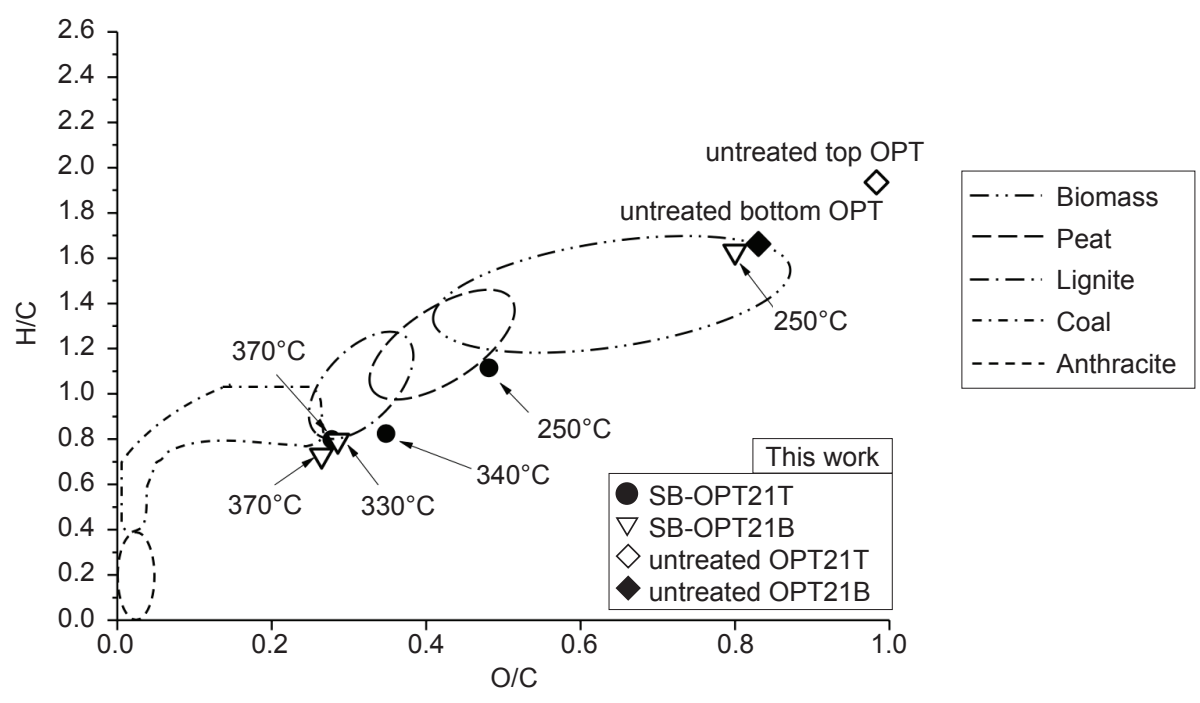

Figure 3. Van Krevelen plots of untreated oil palm trunk (OPT) (dry OPT) and solid biochar (SB) obtained by sub-critical water (sub-CW) reaction.

\section{Van Krevelen Plot of SB}

Figure 3 shows the Van Krevelen plots of untreated OPT (dry OPT) and SB obtained by the sub-CW reaction. The plot was constructed based on the $\mathrm{C}, \mathrm{H}, \mathrm{N}, \mathrm{S}, \mathrm{O}$ contents and the atomic ratios of $\mathrm{O} / \mathrm{C}$ and $\mathrm{H} / \mathrm{C}$ of untreated $\mathrm{OPT}$, and SB of OPT21T and OP21B listed in Table 3. The results showed the $\mathrm{H} / \mathrm{C}$, and $\mathrm{O} / \mathrm{C}$ ratios decreased with increasing reaction temperature. It is because as temperature increases, the pyrolysis reaction of sub-CW becomes more active. Thus, more OPT was decomposed into low molecular hydrocarbon by releasing hydrogen and oxygen into non-condensable gases as a result of hydration, decarboxylation and decarbonylation reactions (Kim et al., 2011; Yi et al., 2009), thus lowering the hydrogen and oxygen content in the SB. The C and $\mathrm{N}$ contents of OPT-derived SB are near to the biochar reported in the literature (Dugan et al., 2010; Karhu et al., 2011). These findings unveil the potential of the SB as a soil enhancement to increase crop productivity, increase $\mathrm{CH}_{4}$ intake and soil water holding capacity. 
TABLE 3. CARBON (C), HYDROGEN (H), NITROGEN (N), SULPHUR (S), OXYGEN (O) CONTENT AND ATOMIC RATIO OF O/C AND H/C OF UNTREATED OIL PALM TRUNK (OPT), AND SOLID BIOCHAR (SB) OF OPT21T AND OPT21B (reaction time: $5 \mathrm{~min}$ )

\begin{tabular}{|c|c|c|c|c|c|c|c|c|}
\hline \multirow{2}{*}{ Treatment } & \multirow{2}{*}{ Position } & $\mathrm{C}$ & $\mathbf{H}$ & $\mathbf{N}$ & $\mathrm{S}$ & $\mathrm{O}^{*}$ & \multirow{2}{*}{$\begin{array}{c}\text { Atomic } \\
\text { O/C }\end{array}$} & \multirow{2}{*}{$\begin{array}{c}\text { Atomic } \\
\text { H/C }\end{array}$} \\
\hline & & & & $(\%)$ & & & & \\
\hline \multirow{2}{*}{ Untreated OPT } & Top & 40.38 & 6.56 & 0.12 & 0.05 & 52.89 & 0.98 & 1.94 \\
\hline & Bottom & 44.52 & 6.20 & 0.19 & 0.05 & 49.04 & 0.83 & 1.66 \\
\hline Solid biochar & Position & $\mathrm{C}$ & $\mathrm{H}$ & $\mathrm{N}$ & $S$ & $\mathrm{O}^{*}$ & $\begin{array}{c}\text { Atomic } \\
\mathrm{O} / \mathrm{C}\end{array}$ & $\begin{array}{c}\text { Atomic } \\
\mathrm{H} / \mathrm{C}\end{array}$ \\
\hline $250^{\circ} \mathrm{C}$ & Top & 56.86 & 5.30 & 1.20 & 0.09 & 36.55 & 0.48 & 1.11 \\
\hline $330^{\circ} \mathrm{C}$ & & 64.19 & 4.42 & 1.37 & 0.12 & 29.90 & 0.35 & 0.82 \\
\hline $370^{\circ} \mathrm{C}$ & & 68.34 & 4.55 & 1.48 & 0.19 & 25.44 & 0.28 & 0.79 \\
\hline $250^{\circ} \mathrm{C}$ & Bottom & 47.85 & 5.94 & 0.24 & 0.04 & 45.93 & 0.72 & 1.48 \\
\hline $330^{\circ} \mathrm{C}$ & & 42.47 & 3.22 & 0.62 & 0.15 & 53.54 & 0.95 & 0.90 \\
\hline $370^{\circ} \mathrm{C}$ & & 50.67 & 3.74 & 1.34 & 0.24 & 44.01 & 0.65 & 0.88 \\
\hline
\end{tabular}

Note: *Oxygen $(\mathrm{O})=100$-carbon $(\mathrm{C})$ - hydrogen $(\mathrm{H})$ - nitrogen $(\mathrm{N})$ - sulphur $(\mathrm{S})$.

Based on the Van Krevelen plot, the SB produced from OPT21B at $250^{\circ} \mathrm{C}$ was still in the biomass region, this showed that the OPT was not fully decomposed into $\mathrm{SB}$ at a temperature below $250^{\circ} \mathrm{C}$. As temperature increased from $250^{\circ} \mathrm{C}$ to $330^{\circ} \mathrm{C}$ and $370^{\circ} \mathrm{C}$, the $\mathrm{SB}$ was in the lignite and coal region, respectively. That indicates, at temperatures of around $330^{\circ} \mathrm{C}$, the OPT had already converted into SB. Meanwhile, the SB obtained from OPT21T at $250^{\circ} \mathrm{C}$ was already out of biomass region and close to peat region, suggesting that OPT21T was easy to decompose into SB compared to OPT21B. As sub$\mathrm{CW}$ temperature increased to $340^{\circ} \mathrm{C}$ and $370^{\circ} \mathrm{C}$, the SB obtained was near to the lignite and also in the coal region, respectively (Van de Weerdhof, 2010). It shows that at high reaction temperature, the SB produced from OPT21T and OPT21B showed the same behaviour. The Van Krevelen plot is supported by the HHV of SB reported in the previous subtopic.

\section{Scanning Electron Microscope (SEM) Images of Untreated OPT and SB}

Figure 4 shows the images of untreated OPT of OPT21T and OPT21B. The OPT21T shows a covered regular round-shaped starch granule, small-sized starch granule and high surface area. Meanwhile, OPT21B shows irregular-shaped, large-sized starch granule with low surface area. The small starch granule size and high surface area explained how OPT21T was easier to decompose than OPT21B.

Figure 5 displays the SEM images of the treated $\mathrm{SB}$ of OPT21T by the sub-CW reaction. Figure $5 a$ $\left(250^{\circ} \mathrm{C}\right)$, showed the surface view of the starch granule where a rupture of starch granule by sub-CW reaction was occurred. The structure of SB (ruptured starch granule and parts of SB) was different compared to untreated OPT21T as shown in Figure 4a. It has proved that at low reaction temperature $\left(250^{\circ} \mathrm{C}\right), \mathrm{OPT} 21 \mathrm{~T}$ was already decomposed into valuable materials and part of SB.
At $340^{\circ} \mathrm{C}$ and $370^{\circ} \mathrm{C}$, the structure of $\mathrm{SB}$ appeared as spherical micro-particle, and the size gradually decreased with the increase in temperature. The small-sized particle provides a high surface area which has the potential to be used as a soil amendment. Figure 6 shows the SEM images of treated SB of OPT21B by sub-CW reaction at different reaction temperatures. At $250^{\circ} \mathrm{C}$, the structure of SB was similar to the untreated OPT21B as shown in Figure $4 b$. This indicated that OPT was not fully decomposed at $250^{\circ} \mathrm{C}$, thus proved the high value in Figure 1. At $330^{\circ} \mathrm{C}$ and $370^{\circ} \mathrm{C}$, the $\mathrm{SB}$ had spherical micro-sized particles which indicate OPT-derived SB could be an excellent soil amendment.

In contrast, the surface structures of SB from OPT and Meranti wood sawdust char obtained by normal pyrolysis reaction showed void spaces, cracks, holes and pores on its surface (Abnisa et al., 2013a; Mazlan et al., 2015). This distinction suggested that the presence of water in the sub-CW reaction is responsible for the morphological variances because the only significant difference between these reactions was the usage of water. Consequently, this could be the advantage of using sub-CW technology although further verification is needed.

\section{Particle Size Distribution of SB Produced by sub- CW Technology}

Treatment of OPT using sub-CW technology produced spherical micro-sized particles of SB as illustrated by SEM images in Figures 5 and 6 . Even though there are still starch granule observed in the SB (Figures $5 b$ to $5 c$ and Figures $6 b$ to $6 c$ ), the particle size distribution of the SB was required to be determine as to measure the exact size of the SB. Therefore, their particle size distributions were measured. Figure 7 show the results of the particle size distribution of SB produced by the sub-CW reaction. It is worth noting that the particle size for treated of OPT21B was distributed into two peaks 
as shown in Figure 7a. The first peak with the smallsized particle was attributed to the single particle size of SB, while the second peak with the largesized particle was probably due to agglomeration of the small-sized particles that occurred during the sub-CW reaction. For treated of OPT21T as in Figure $7 b$, the particle size distributions showed one peak when treated at $250^{\circ} \mathrm{C}$ and $340^{\circ} \mathrm{C}$, but two peaks at $370^{\circ} \mathrm{C}$.

On sub-CW treatment at $250^{\circ} \mathrm{C}$, the particle size of SB from OPT21T was $120 \mu \mathrm{m}$, which was larger than the SB from OPT21B $(80 \mu \mathrm{m})$. Meanwhile, for treatment at $340^{\circ} \mathrm{C}(\mathrm{OPT} 21 \mathrm{~T})$ and $330^{\circ} \mathrm{C}(\mathrm{OPT} 21 \mathrm{~B})$, the particle size of SB was almost similar (17 and 20 $\mu \mathrm{m})$. For treatment at $370^{\circ} \mathrm{C}$, the peak size of smallsized particle SB from OPT21T was the same as the OPT21B $(8 \mu \mathrm{m})$. The peak size of the large-sized particle for the SB from OPT21T $(630 \mu \mathrm{m})$ was larger than SB from OPT21B $(360 \mu \mathrm{m})$. The variations in the particle size of SB at different reaction temperature proved the hydrolysis and pyrolysis reaction occurred in sub-CW treatment. A large particle size of SB observed at $250^{\circ} \mathrm{C}$ showed a product from hydrolysis reaction. The small particle size of SB observed from $330^{\circ} \mathrm{C}$ to $370^{\circ} \mathrm{C}$ showed a product of pyrolysis reaction.

Table 4 lists the areas of the small $\left(A_{\mathrm{S}}\right)$, and large $\left(A_{\mathrm{L}}\right)$ sized particle peaks, together with the ratio between the large and small peaks $\left(A_{\mathrm{L}} / A_{\mathrm{S}}\right)$. For the sub-CW treatment of the bottom part, $A_{\mathrm{L}} / A_{\mathrm{S}}$ increased from 0.44 to 1.47 with elevating treatment temperatures. This increase could be attributed to the agglomeration of the particles at higher pyrolysis temperature causing the increase in the larges sized particles. Treatment of the bottom part at $370^{\circ} \mathrm{C}$ resulted in $A_{\mathrm{L}} / A_{\mathrm{S}}=1.47$, which was larger than the top part $A_{\mathrm{L}} / A_{\mathrm{S}}=0.61$ at the same treatment temperature. This difference might change somehow due to the variance in the lignocellulosic composition, vascular bundle and parenchyma tissues of both portions despite taken from the same tree. Subsequently, treatment of OPT with sub-CW produced microparticle SB that can be utilised as biochar to improve soil productivity and carbon sequestration.
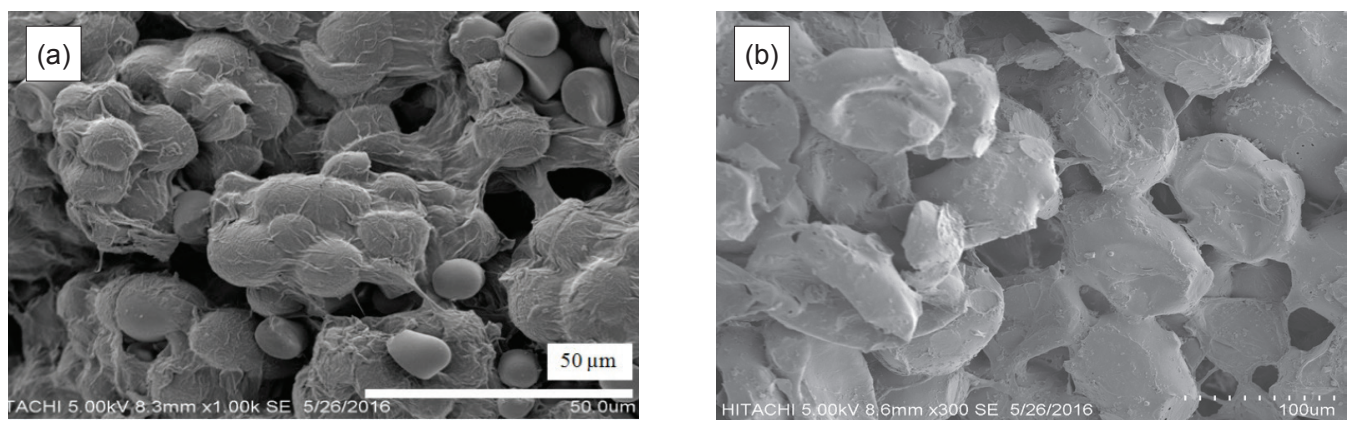

Figure 4. Scanning electron microscope (SEM) images of untreated oil palm trunks: (a) 21-year old oil palm trunk (OPT) top section (OPT21T) and (b) 21-year old OPT bottom section (OPT21B).
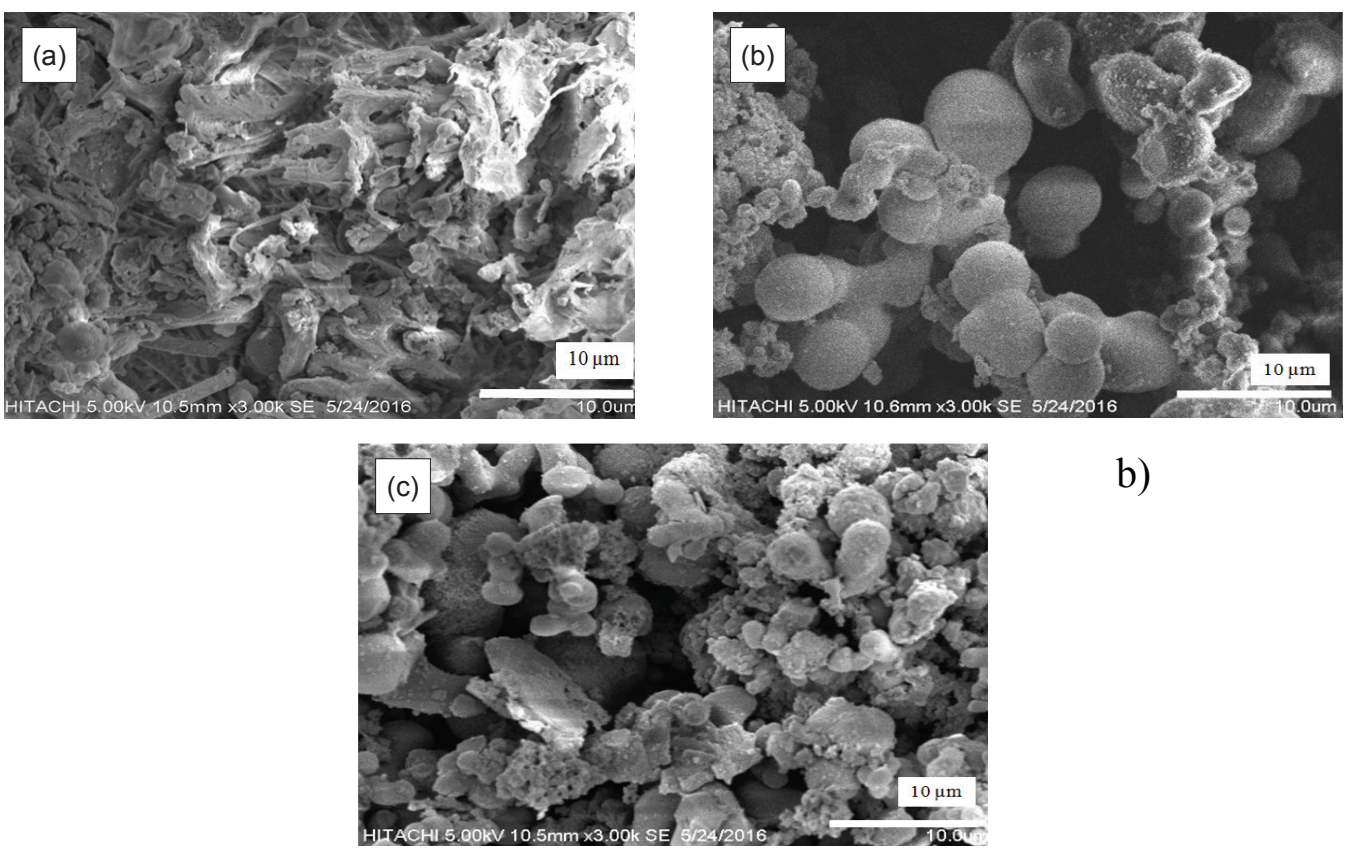

Figure 5. Scanning electron microscope (SEM) images of treated solid biochar (SB) for 21-year old oil palm trunk (OPT) top section (OPT21T) by sub-critical water (sub-CW) pyrolysis reaction at reaction temperature (a) $250^{\circ} \mathrm{C},(b) 340^{\circ} \mathrm{C}$ and (c) $370^{\circ} \mathrm{C}$. 

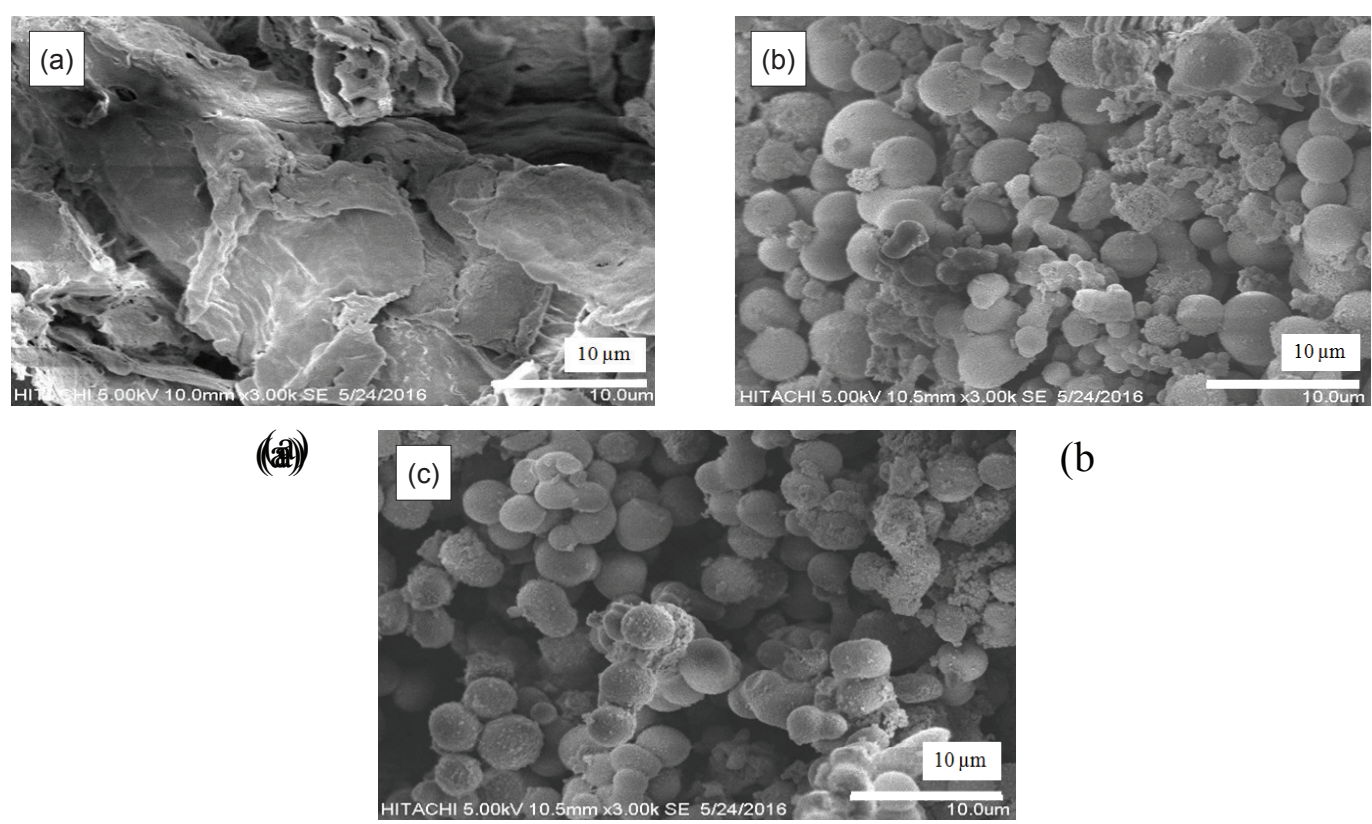

Figure 6. Scanning electron microscope (SEM) images of treated solid biochar (SB) for OPT21B by sub-critical water (sub-CW) pyrolysis reaction at reaction temperature (a) $250^{\circ} \mathrm{C}$, (b) $330^{\circ} \mathrm{C}$ and (c) $370^{\circ} \mathrm{C}$.
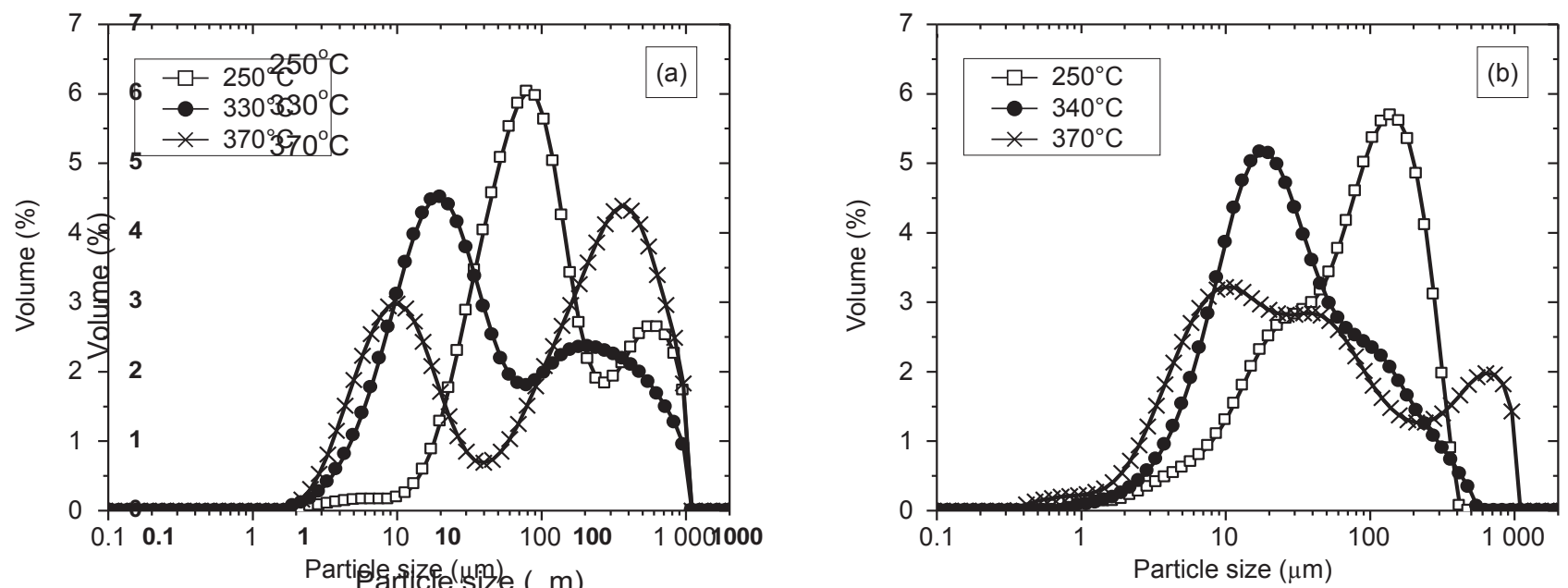

Figure 7. Particle size distribution of solid biochar (SB) produced by sub-critical water (sub-CW) pyrolysis reaction: (a) 21-year old oil palm trunk $(\mathrm{OPT})$ bottom section (OPT21B) and (b) 21-year old OPT top section (OPT21T).

TABLE 4. PEAK OF PARTICLE SIZE DISTRIBUTION OF SOLID BIOCHAR (SB) OBTAINED BY SUB-CRITICAL WATER (sub-CW) PYROLYSIS REACTION

\begin{tabular}{|c|c|c|c|c|c|}
\hline \multirow[b]{2}{*}{$\begin{array}{c}\text { Temperature } \\
\left({ }^{\circ} \mathrm{C}\right)\end{array}$} & \multicolumn{2}{|c|}{ Smaller-size particle } & \multicolumn{2}{|c|}{ Larger-size particle } & \multirow[b]{2}{*}{ Peak area ratio $\left(A_{L} / A_{S}\right)$} \\
\hline & $\begin{array}{c}\text { Peak size }(S) \\
(\mu \mathrm{m})\end{array}$ & $\begin{array}{c}\text { Peak area }\left(\mathrm{A}_{\mathrm{s}}\right) \\
(\%)\end{array}$ & $\begin{array}{c}\text { Peak size }(\mathrm{L}) \\
(\mu \mathrm{m})\end{array}$ & $\begin{array}{c}\text { Peak area }\left(\mathrm{A}_{\mathrm{L}}\right) \\
(\%)\end{array}$ & \\
\hline \multicolumn{6}{|l|}{ (a) Bottom part } \\
\hline 250 & 80 & 6.03 & 550 & 2.64 & 0.44 \\
\hline 330 & 20 & 4.51 & 200 & 2.39 & 0.53 \\
\hline 370 & 8 & 2.98 & 360 & 4.39 & 1.47 \\
\hline \multicolumn{6}{|l|}{ (b) Top part } \\
\hline 250 & 120 & 5.69 & nd & nd & na \\
\hline 340 & 17 & 5.16 & nd & nd & na \\
\hline 370 & 8 & 3.22 & 630 & 1.98 & 0.61 \\
\hline
\end{tabular}

Note: nd - not determined. na - not available. 


\section{CONCLUSION}

The possibility of using sub-CW to produce SB was studied. The conclusions of the present study are listed as follows:

- The highest production of SB was $0.18 \mathrm{~kg} \mathrm{kg-}$ dry $\mathrm{OPT}^{-1}\left(300^{\circ} \mathrm{C}, 5 \mathrm{~min}\right)$ obtained from the OPT21T.

- The highest HHV of SB was $32.4 \mathrm{MJ} \mathrm{kg}^{-1}$ produced by OPT21B, this signifies sub$\mathrm{CW}$ able to convert OPT into solid fuel with significant HHV.

- The SB produced from sub-CW treatment of the OPT21T contained a larger quantity of microsized particles compared to the OPT21B.

Therefore, the results from this study concluded that sub-CW technology could be utilised to produce high-quality spherical micro-particle SB, which can be a good candidate as an alternative fuel, adsorbent (water and air pollutant), and soil amendments.

\section{ACKNOWLEDGEMENT}

This study was supported by the government of Malaysia through the Ministry of Education under Fundamental Research Grant Scheme (5524505).

\section{REFERENCES}

Abnisa, F; Arami-Niya, A; Daud, W M A W and Sahu, J N (2013a). Characterization of bio-oil and bio-char from pyrolysis of palm oil wastes. Bioenergy Research, 6(2): 830-840.

Abnisa, F; Arami-Niya, A; Wan Daud, W M A; Sahu, J N and Noor, I M (2013b). Utilization of oil palm tree residues to produce bio-oil and bio-char via pyrolysis. Energy Conversion and Management, 76: 1073-1082.

Dayang Nazrima, S (2017). Malaysian Palm Oil Board (MPOB). http:/ / www.mpob.gov.my/, accessed on 22 December, 2018.

Demirbas, A (2004). Determination of calorific values of bio-chars and pyro-oils from pyrolysis of beech trunkbarks. J. Analytical and Applied Pyrolysis, 72(2): 215-219.

Dugan, E; Anne, V; Steve, R and Saran, S (2010). Bio-char from sawdust, maize stover and charcoal: Impact on water holding capacities (WHC) of three soils from Ghana. 19 $9^{\text {th }}$ World Congress of Soil Science, Soil Solution for a Changing World. p. 8-12.
Hossain, N and Jalil, R (2016). Sugar and bioethanol production from oil palm trunk (OPT). Asia Pacific J. Energy and Environment, 2(2): 81-84.

Hunt, J; Duponte, M; Sato, D and Kawabata, A (2010). The basics of biochar: A natural soil amendment. Soil and Crop Management, SCM-30. p. 1-6.

Ibrahim, W A (2012). Converting Waste Oil Palm Trees into a Resource. United Nations Environment Programme, Osaka, Japan. 203 pp.

Jalil, R; Ibrahim, W A; Elham, P and Sarif, M (2011). Towards zero waste production of value added products from waste oil palm trunk (WOPT). $8^{\text {th }}$ Biomass Asia Workshop. Hanoi, Vietnam. p. 1-7.

Kalyana, S and Basiron, Y (2017). The oil palm tree. http://www.mpoc.org.my/, accessed on 8 February 2017.

Kan, T; Strezov, V and Evans, T J (2016). Lignocellulosic biomass pyrolysis: A review of product properties and effects of pyrolysis parameters. Renewable and Sustainable Energy Reviews, 57: 126-1140.

Karhu, K; Mattila, T; Bergström, I and Regina, K (2011). Biochar addition to agricultural soil increased ch 4 uptake and water holding capacity - Results from a short-term pilot field study. Agriculture, Ecosystems and Environment, 140(1-2): 309-313.

Kee, K (2004). Nutrient reserves and recycling from oil palm trunks at replanting. Crop ScienceICSC2004. p. 1-4.

Kim, P; Johnson, A; Edmunds, C W; Radosevich, M; Vogt, F; Rials, T G and Labbé, N (2011). Surface functionality and carbon structures in lignocellulosic-derived biochars produced by fast pyrolysis. Energy and Fuels, 25(10): 4693-4703.

Kosugi, A; Tanaka, R; Magara, K; Murata, Y; Arai, T; Sulaiman, O and Mori, Y (2010). Ethanol and lactic acid production using sap squeezed from old oil palm trunks felled for replanting. J. Bioscience and Bioengineering, 110(3): 322-325.

Kurnin, N A A; Ismail, M H S; Hiroyuki, Y and Izhar, S (2016). Recovery of palm oil and valuable material from oil palm empty fruit bunch by subcritical water. J. Oleo Science, 289(4): 283-289.

Lam, M K; Tan, K T; Lee, $\mathrm{K} \mathrm{T}$ and Mohamed, A R (2009). Malaysian Palm Oil: Surviving the Food Versus Fuel Dispute for a Sustainable Future, 13: 14561464. 
Liu, Z and Han, G (2015). Production of solid fuel biochar from waste biomass by low temperature pyrolysis. Fuel, 158: 159-165.

Liu, Z; Quek, A; Kent Hoekman, S and Balasubramanian, R (2013). Production of solid biochar fuel from waste biomass by hydrothermal carbonization. Fuel, 103: 943-949.

Luque De Castro, M D; Jimenez-Carmona, M M and Fernandez-Perez, V (1999). Towards more rational techniques for the isolation of valuable essential oils from plants. Trends in Analytical Chemistry, 18(11): 708-716.

Mazlan, M A F; Uemura, Y; Osman, N B and Yusup, $S$ (2015). Characterizations of bio-char from fast pyrolysis of Meranti wood sawdust. J. Physics: Conference Series, 622(1): 1-7.

Muda, N A; Yoshida, H; Ishak, H; Ismail, M H S and Izhar, S (2019). Conversion of oil palm trunk into bio-oil via treatment with sub- critical water. J. Wood Chemistry and Technology, 39(4): $1-17$.

Mukherjee, A; Lal, R and Zimmerman, A R (2014). Effects of biochar and other amendments on the physical properties and greenhouse gas emissions of an artificially degraded soil. Science of the Total Environment, 487: 26-36.

Norhazimah, A H and Faizal, C K M (2014). Bioconversion of oil palm trunks sap to bioethanol by different strains and co-cultures at different temperatures. J. Medical and Bioengineering, 3(4): 297-300.

Ortega, J H (2015). Process Design of Lignocellulosic Biomass Fractionation into Cellulose, Hemicellulose and Lignin by Prehydrolysis and Organosolv Process. M.Sc. thesis. Wageningen University, Netherlands. 36 pp.

Peterson, A A; Vogel, F; Lachance, R P; Fröling, M; Antal, Jr M J and Tester, J W (2008). Thermochemical biofuel production in hydrothermal media: A review of sub- and supercritical water technologies. Energy and Environmental Science, 1(1): 32-65.

Pourali, O (2010). Production of Valuable Materials from Rice Bran Biomass Using Subcritical Water. Ph.D thesis. Osaka Prefecture University, Japan. 131 pp.

Pourali, O; Asghari, F S and Yoshida, H (2009). Sub-critical water treatment of rice bran to produce valuable materials. Food Chemistry, 115(1): 1-7.
Shitu, A; Izhar, S and Tahir, T (2015). Sub-critical water as a green solvent for production of valuable materials from agricultural waste biomass: A review of recent work. Global J. Environ. Sci. Manage., 1(3): 255-264.

Sun, J; Hoon, S; Jung, S; Ryu, C; Jeon, J; Shin, M and Park, Y (2016). Production and utilization of biochar: A review. J. Industrial and Engineering Chemistry, 40: $1-15$.

US Department of Energy (2011). Biomass Energy Data Book. $4^{\text {th }}$ Edition. 254 pp. http: / / cta.ornl.gov/ bedb

Valdez, P J; Dickinson, J G and Savage, P E (2011). Characterization of product fractions from hydrothermal liquefaction of Nannochloropsis sp. and the influence of solvents. Energy and Fuels, 25(7): 3235-3243.

Van De Weerdhof, MW (2010). Modeling the Pyrolysis Process of Biomass Particles. Ph.D thesis. Eindhoven University of Technology, Netherlands. 70 pp.

Venderbosch, R and Prins, W (2010). Fast pyrolysis technology development. Biofuels, Bioproducts and Biorefining, 4(3): 178-208.

Yamada, H; Tanaka, R; Sulaiman, O; Hashim, R; Hamid, Z A A; Yahya, M K A and Mori, Y (2010). Old oil palm trunk: A promising source of sugars for bioethanol production. Biomass and Bioenergy, 34(11): 1608-1613.

Yang, H; Yan, R; Chen, H; Lee, D H and Zheng, C (2007). Characteristics of hemicellulose, cellulose and lignin pyrolysis. Fuel, 86(12-13): 1781-1788.

Yi, B K; Ma, C Y; Chen, G F and Chen, S Y (2009). Study on pyrolysis of used tyre in subcritical and supercritical water. 2009 International Conference on Energy and Environment Technology, ICEET 2009. p. 779-782.

Yoshida, H; Izhar, S; Nishio, E; Utsumi, Y; Kakimori, $\mathrm{N}$ and Salak Asghari, F (2018). Application of sub-critical water for recovery of tin and glass substrates from lcd panel e-waste. Detritus, 04: 98103.

Zhang, A; Bian, R; Pan, G; Cui, L; Hussain, Q and Li, L (2012). Effects of biochar amendment on soil quality, crop yield and greenhouse gas emission in a chinese rice paddy: A field study of 2 consecutive rice growing cycles. Field Crops Research, 127: 153160. 